\title{
Study on "carbon curse" effect of china under the Belt and Road
}

\author{
Du Mengchen * \\ International Business School \\ Yunnan University of Finance and Economics \\ Kunming, China \\ 798086261@qq.com
}

\author{
Liang Linlin \\ International Business School \\ Yunnan University of Finance and Economics \\ Kunming, China \\ 279653205@qq.com
}

\begin{abstract}
The greenhouse effect is serious in the world. China is a big country of carbon dioxide emissions. In recent years, sustainable development is put forward that China's environmental policy has been changed to green ecology. Under the background of "The Belt and Road", we should bring China's cultural ecology to neighboring countries. According to the above situation, this paper puts forward the hypothesis of "carbon curse" in China, and the carbon emissions from fossil fuel reserves and energy consumption in 31 provinces and cities of China during 2005-2014 were measured. The research results show that China's "carbon curse" problem is not very clear, there are a lot of factors that affect the carbon emissions.
\end{abstract}

Keywords-carbon curse; carbon emissions; fossil fuels; energy reserves; regional differences

\section{INTRODUCTION}

In the "The Belt and Road" strategy, green economy, energy saving and environmental protection cannot be ignored. As an economic power, China has the ability and responsibility to provide better experience, more clean technology, better green services to other less developed countries and regions. Global warming caused by $\mathrm{CO} 2$ concentration rising has become a serious challenge to human survival and development, more and more scholars do analysis and research on energy and carbon emissions. More than thirty years of reform and opening up, China has sustained and rapid growth of economic, creating a "China miracle", but also paid a huge costs on energy and environmental. Chinese development issues of not balanced, coordinated and sustainable are still outstanding, the situation is not optimistic about the carbon emissions.

From the $\mathrm{CO}_{2}$ emissions and the content of three major fossil fuels (coal, oil, natural gas) in the provinces of China, it is thought that "carbon curse" in China is serious, that is, fossil energy reserves doomed to high $\mathrm{CO} 2$ emission in China.

\section{LITERATURES REVIEW}

Literatures on carbon dioxide emissions and regional differences mainly concentrated in the areas of carbon dioxide emissions and economic development [1], the relationship between carbon emission intensity and the difference of energy resources [2], carbon dioxide emissions in the driving

\footnotetext{
* Corresponding author
}

factors and driving factors of carbon intensity difference research [3], the decoupling theory and CKC empirical analysis, empirical analysis of the panel data, the total factor productivity index of non-parametric model, LMDI decomposition model and a series of econometric methods to get the energy consumption structure, energy consumption intensity, income, population and other factors are the main factors of regional differences in carbon emissions [5]. Cai Rongsheng from the perspective of regional energy endowments analysis show the carbon emission intensity differences at the regional level from the perspective of regional energy endowments and proposed the conclusion based on the theoretical analysis: Higher energy endowment, lower the pressure of shortage of energy and use, so that the power of technological progress is insufficient, not to seek the transformation of the mode of economic development, industrial structure upgrade and inertia to rely on traditional high energy consumption and low level industry, at last still follow the economic development path of high energy consumption and high carbon intensity [2].

Starting from the relationship between carbon emissions and three major fossil fuels (coal, oil, natural gas) reserves in the provinces of China, proposed the hypothesis of carbon curse in China, in other words, $\mathrm{CO}_{2}$ emission intensity is high where the fossil energy reserves are high in China, reserves of fossil energy is directly proportional to $\mathrm{CO}_{2}$ emissions.

\section{REGIONAL EMPIRICAL ANALYSIS OF CARBON EMISSION IN CHINA}

The word "carbon curse" is proposed in a paper "The carbon curse: Are fuel rich countries doomed to high $\mathrm{CO}_{2}$ intensities?" by Jörg Friedrichs and Oliver R. Inderwildi, the text associated a country's fossil fuels with carbon intensity, proposed that fuel rich countries doomed to high $\mathrm{CO} 2$ intensities [4].

The "resource curse" is used to illustrate that rich natural resources may be a curse of economic development rather than a blessing, and that most countries with rich natural resources are growing more slowly than those with scarce resources. "Carbon curse" is also used to show that the fossil fuel rich region is more likely to rely on rich local mineral deposits, so that appear the phenomenon of low output, high emissions. The "carbon curse" is not a static concept, but a dynamic one. The 
core of this new theory is that the richness of fossil fuels in a country determines the carbon intensity of the country to a large extent.

\section{A. Energy status quo empirical analysis}

This paper comprehensively considered three aspects of coal reserves, oil reserves and natural gas reserves, analysis of the situation in 31 regions of the country (including provinces, autonomous regions and municipalities). Sample interval is 2005-2014 years. Therefore, the research sample is a data set that contains 31 regions, the time span is 10 years, and has a large information capacity. The related data used in this paper comes from the "China Statistical Yearbook", "China Statistical Yearbook", "China's Industrial Economic Statistical Yearbook", the Yearbooks of provinces (cities, districts) and the data of the National Bureau of statistics.

The current situations are shown in figure 1 to 3 .

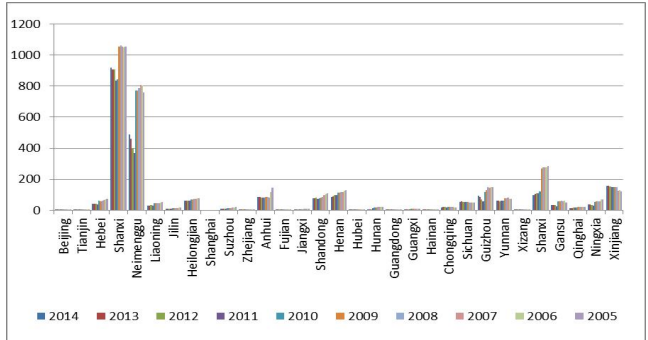

Fig. 1. 2005-2014 coal reserves of all provinces in China (100 million tons)

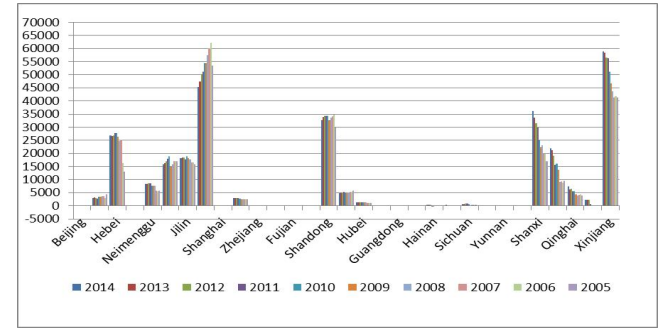

Fig. 2. 2005-2014 national oil reserves of all provinces (10000 tons)

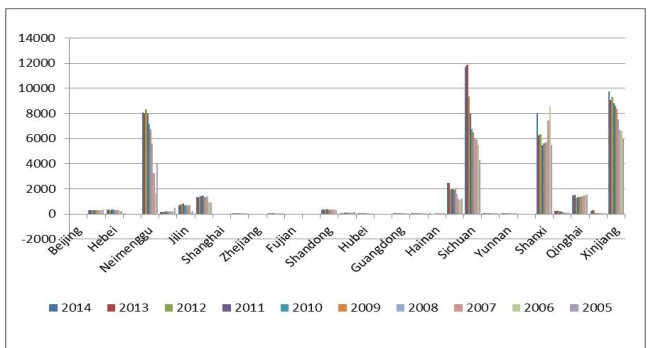

Fig. 3. 2005-2014 national natural gas reserves in various provinces (100 million tons)

\section{B. Current situation of carbon emission}

To coal, oil and natural gas these three primary energy sources as the benchmark to calculate the $\mathrm{CO}_{2}$ emissions of domestic provinces, the calculating formula is as follow:

$$
\mathrm{C}_{\mathrm{t}}=\Sigma \mathrm{C}_{\mathrm{i}, \mathrm{t}}=\Sigma \mathrm{E}_{\mathrm{i}, \mathrm{t}} \times \mathrm{NCV}_{\mathrm{i}} \times \mathrm{CEF}_{\mathrm{i}} \times \mathrm{COF}_{\mathrm{i}} \times(44 /
$$

Among them, the $\mathrm{C}$ representative estimates of $\mathrm{CO}_{2}$ emissions (units of 10 million $\mathrm{T}$ ), $\mathrm{i}=1,2,3$, respectively on behalf of three primary energy (coal, crude oil and natural gas), $\mathrm{E}$ on behalf of energy consumption. NCV is the mean low calorific value of three primary sources of energy mentioned. CEF is carbon emission coefficient provided by the IPCC (2006) "greenhouse gas inventory". COF is the carbon oxidation factors. 44 and 12 are the molecular weight of $\mathrm{CO}_{2}$ and carbon respectively.

We calculated the $\mathrm{CO}_{2}$ emissions and showed in figure 4 to 6 .

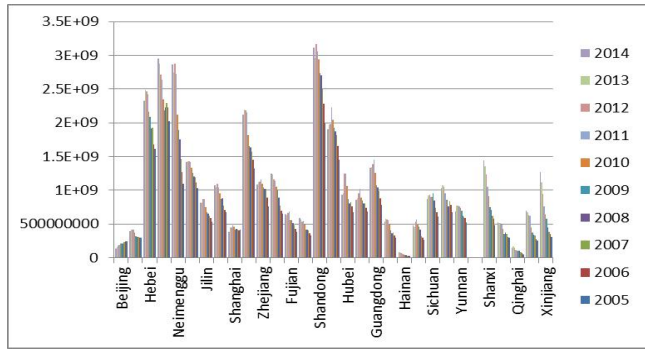

Fig. 4. 2005-2014 CO2 emissions from coal in the provinces

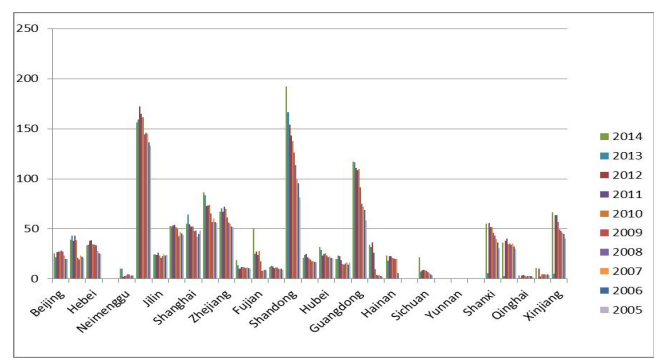

Fig. 5. 2005-2014 CO2 emissions from national oil in the provinces

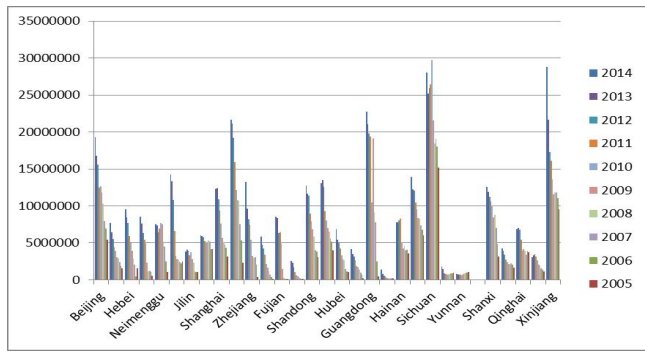

Fig. 6. 2005-2014 CO2 emissions from national natural gas in the provinces

\section{Research conclusion}

Based on the above research, the assumptions made in the beginning of the article are as follows:

1) $\mathrm{CO} 2$ emissions from various provinces and municipalities in China have great differences. From total carbon emissions, $\mathrm{CO} 2$ emissions in the eastern region ranked first, the Mid-region and the west were second and third. CO2 emissions from 2005 to 2010 increased year by year, but from the beginning of 2010 decreased year by year, indicating that during our country "the 12th Five-Year", "the 13th Five-Year" energy-saving emission reduction work is in place. 
2) In general, carbon dioxide emissions are in direct proportion to the local fossil fuel reserves, but the individual regions are not so. For example, the most abundant coal reserves in Shanxi Province and Inner Mongolia Autonomous Region, but coal consumption caused by carbon dioxide emissions in Shandong Province is really quite high; gas reserve area is Shanghai and Xinjiang Uyghur Autonomous Region, but oil consumption caused by carbon dioxide emissions does Shandong and Jilin highest; natural gas reserves of Shandong Province is very low, but the use of natural gas volume caused by carbon dioxide emissions but ranking.

\section{CONCLUSION}

Overall, areas with high reserves of fossil fuels are high with the trend of $\mathrm{CO}_{2}$ emissions, but there are also some other factors that affect the $\mathrm{CO}_{2}$ 's emissions. Some areas of fuel reserves are high, but there did not have high volume of $\mathrm{CO}_{2}$ that corresponding to it. Economic growth has contributed to the increase in $\mathrm{CO}_{2}$ emissions, while the decline in energy usage has inhibited the increase in per capita $\mathrm{CO}_{2}$ emissions. The growth of economy is the determining factor of the increase of $\mathrm{CO}_{2}$ emission. The use of energy made a negative effect on the increase of per capita $\mathrm{CO}_{2}$ emissions. But because of the economic growth and energy structure change, the positive contributions to the $\mathrm{CO}_{2}$ emission are fighting with the negative contributions to the energy use. Energy usage can be further decomposed into the impact of energy consumption and industrial structure of the two industries. Although the change of industrial structure has promoted the increase of energy consumption in general, but the decline in energy consumption among all industries is the decisive factor in the decline of total energy consumption.

According to the conclusions, to achieve China's carbon emission reduction targets in 2020,we must be based on each region. Combined with the influence factors of $\mathrm{CO} 2$ emission growth in this paper, we promote the influence factors of carbon emissions, implement differentiation strategies to reduce emissions, promote the transformation of low carbon economic development models step by step, finally, we get the following policy implications:

\section{1) Optimize the structure of regional energy}

At this stage, all regions can further reduce the proportion of coal consumption, gradually optimize the regional energy structure, reduce carbon dioxide emissions by the development of new energy and renewable energy.

\section{2) Reduce regional energy intensity}

Energy resources are relatively scarce in the eastern regions, but the energy utilization efficiency is relatively high, and the energy intensity is the lowest. The central and western regions are rich in energy resources, but the energy utilization efficiency is relatively low, energy intensity and $\mathrm{CO} 2$ emission intensity are significantly higher than that in the eastern regions. At the present stage, we should establish the mechanism of regional energy resources development and utilization, and resolutely crack down on some behaviors like deforestation, indiscriminate exploitation, indiscriminate digging and so on that destruct environmental resources. At the same time, we develop low carbon technology actively through scientific and technological innovation, aiming at improving the efficiency of energy use, reducing regional energy intensity, and controlling regional carbon dioxide emissions.

\section{3) Adjust regional industrial structure}

In the course of the study, we found that the change of industrial structure has improved the energy intensity of each region, further promote the increase of carbon dioxide emissions in each region. At this stage, we should control the proportion of the second industry, eliminate high energy consuming industries, improve the access threshold of "high carbon" industry, develop high-tech industry and modern service industry, expand the proportion of the third industry, optimize and adjust industrial structure, to decrease energy intensity, and reduce carbon dioxide emissions.

\section{4) Nomic growth mode}

All regions must abandon the high investment, high emissions, high pollution of the high carbon economic growth models, and actively promote the transformation of regional low-carbon economic growth mode.

We should make full use of the favorable opportunity of "The Belt and Road" strategy and strengthen regional cooperations, optimize the layout of domestic industry chain , promote the coordinated development of different regions in China.

Facing the new situation and new challenges, "The Belt and Road" strategy put forward new ideas for the balance of regional development, to promote China's regional industrial balanced development is of great significance. "The Belt and Road" strategy put forward new ideas for the balance of regional development, and make great significance of promoting China's regional industrial balanced development.

\section{ACKNOWLEDGMENT}

This work was supported by the Science Foundation and Major Project of Educational Committee of Yunnan Province (No. 2014Z100); Applied Basic Research Programs of Yunnan Province (No. 2013FD029, and Philosophy and Social Science Foundation of Yunnan Province (Grant No. YB2015087). At the same time, thank my mentor for the guidance of the paper and the encouragement and care of my classmates.

\section{REFERENCES}

[1] J. Wang, and J. Yang, "Regional carbon dioxide emissions and economic development -- Based on the empirical analysis of decoupling theory and CKC," Journal of Shanxi University of Finance and Economics, vol. 35, 2013, pp. 8-18.

[2] R.S. Cai, and C.Y. Liu, "The relationship between carbon emission intensity and energy endowment--An Empirical Analysis Based on China's Provincial Panel Data," Journal of Yantai University (PHILOSOPHY AND SOCIAL SCIENCES EDITION), 2013.

[3] C. Yue, X.Y. Hu, and C.F. He, "1995 - 2007 China's carbon emissions and carbon intensity of the analysis-- carbon emissions and social development III," Journal of Peking University, vol. 4, 2010. 
[4] Jörg Friedrichs, and Oliver R. Inderwildi, "The carbon curse Are fuel rich countries doomed to high CO2 intensities," Energy Policy, 2013.

[5] B.W. Ang, and F.Q. Zhang, "Inter-regional comparisons of energyrelated CO2emissions using the decomposition technique," Energy, vol. 4, 1999, pp. 297-305.

[6] T.H. Kwon, "Decomposition of factors determining the trend of $\mathrm{CO} 2$ emissions from car travel in Great Britain(1970-2000)," Ecological Economics, vol. 2, 2005, pp. 261-275.

[7] P.B. Stretesky, and M.J. Lynch, "A cross-national study of the association between per capita carbon dioxide emissions and ex-ports," The United States Social Science Research, vo1. 38, 2009, pp. 239-250.

[8] S. Chen, S.Y. Fa, and R.S. Wu, "The relationship deepening of capital, increased productivity and China's carbon dioxide emissions changes-industry, region, the energy of three-dimensional structure adjustment from the perspective of factor decomposition analysis," Finance and economics, vo1. 2, 2010.
[9] B.Y. Song, and F.L. Su, "A panel data analysis on the relationship between the regional carbon emissions and low carbon economy," Journal of Yunnan University of Finance and Economics, vol. 5, 2010.

[10] S.X. Li, H.Y. Ma, and J.H. Cheng, "China's rich coal resources development and economic development performance," China's population Resources and environment, vol. 23, 2013, pp. 12-18.

[11] L. Lei, Y.Y. Zhong, and X.L. Yang, "The regional carbon emissions factor decomposition model and Its Empirical Analysis," Contemporary economy science, vo1. 26, 2011, pp. 104-110.

[12] "National Bureau of statistics. China Statistical Yearbook," Beijing, China Statistics Press, 2015 - 2005

[13] "National Bureau of statistics. China energy statistical yearbook," Beijing, China Statistics Press, $2015-2005$

[14] K. Feng, K. Hubacek, and D. Guan, "Life styles, technology and CO2 emissions in China: A regional comparative analysis," Ecological Economics, vo1. 69, 2009, pp. 145-154 